\section{Caesarean section in a diabetic patient with a recent myocardial infarction}

Jeffrey Spencer MD, ${ }^{*}$ Farida Gadalla MD, ${ }^{*}$

William Wagner MD, $\dagger$ James Blake MD $\ddagger$
This is a report of a 38-yr-old parturient with multiple medical problems including diabetes mellitus, bronchial asthma, chronic myelogenous leukaemia, pre-eclampsia and a recent myocardial infarction. After medical management in the coronary care unit, it was decided to proceed with a Caesarean section. The choice of anaesthetic was made by the patient and had to be modified in accordance with her medical condition. Cardiovascular monitoring included PA catheterisation and transoesophageal echocardiography. A general anaesthetic was performed using fentanyl, thiopentone and succinylcholine. The outcome was satisfactory for both parturient and baby.

Cette observation porte sur le cas d'une parturiente de 38 ans présentant de multiples problèmes dont un diabète, de l'asthme bronchique, une leucémie myelogène chronique, de. la prééclampsie et un infarctus du myocarde récent. Après un séjour à l'unité de soins coronariens pour traitement, une césarienne est décidée. La patiente choisit son anesthésie, choix quil faut modifier pour des raison médicales. Le monitorage cardiovasculaire comprend la cathétérisme de l'artère pulmonaire et l'échographie transoesophagienne. L'anesthésie générale est réalisée avec du thiopentone, du fentanyl et de la succinylcholine. Les résultats sont favorables tant pour la mère que pour l'enfant.

\section{Key words}

ANAESTHESIA: obstetric;

COMPLICATIONS: diabetes, myocardial infarction.

From the Departments of Anesthesiology*, Obstetrics and Gynecology† and Medicinet, The New York Hospital/Cornell Medical Center, New York, NY.

Address correspondence to: Dr. Farida Gadalla, Department of Anesthesiology, The New York Hospital/Cornell Medical Center, 525 East 68th Street, New York, NY 10021.

Accepted for publication 20th February, 1994.
Myocardial infarction is rarely encountered during pregnancy. ${ }^{1,2}$ When it does occur, it threatens the life of both mother and fetus. Maternal mortality approaches 35\%, and $40 \%$ of the deaths occur in the third trimester. ${ }^{3}$ We present a case of Caesarean section in a woman with multiple medical problems who presented five months after myocardial infarction.

Management of this case included preoperative and intraoperative medical management, based on clinical findings and invasive monitoring. Complex case reports with multiple medical problems are rare but are now on the rise due to factors such as an increase in number of patients of advanced maternal age secondary to oocyte donation and surrogate mothers.

We think we will be faced with an increasing number of parturients suffering from ischaemic heart disease, possibly with additional medical problems, and we should be prepared to undertake their management.

\section{Case report}

A 38-yr-old gravida 4, para 2 parturient was admitted to the Coronary Care Unit at $35 \mathrm{wk}$ gestation. She had suffered a silent myocardial infarction five months previously, showing ECG changes associated with an anterolateral myocardial infarction, and poor left ventricular function. She had superimposed mild preeclampsia (increase in urinary protein from $1 \mathrm{~g} \cdot$ day $^{-1}$ to $4 \mathrm{~g} \cdot$ day $^{-1}$ and an increase in weight of $2.3 \mathrm{~kg}$ in one week) as well as accelerating hypertension (144/92 on admission) and congestive heart failure (dyspnoea, grade II/VI systolic ejection murmur and jugular venous distention). Her pregestational White classification of diabetes mellitus was R-F (age of onset nine years, duration $29 \mathrm{yr}$, proliferative retinopathy, nephropathy.) On admission her weight was $68.6 \mathrm{~kg}$; and height $150 \mathrm{~cm}$. The plan of management included improvement of medical status, haemodynamic monitoring, and subsequent delivery.

Her past medical history was notable for hypertension, asthma treated by albuterol, chronic myelogenous leukaemia under suboptimal control (recent WBC $45,300 / \mathrm{mm}^{3}$, platelets $495,000 / \mathrm{mm}^{3}$ ), two previous Cae- 
sarean sections $(1974,1982)$ and an ovarian cystectomy (1982).

Pre-admission ECG revealed an anterolateral myocardial infarction and a diaphragmatic myocardial infarction of indeterminate age. The results of transthoracic two dimensional echocardiography showed a mildly enlarged left atrium, marked left ventricular hypokinesia in the region of the mid-distal septum and posterolateral walls. Global left ventricular function was moderately decreased. Ejection fraction was estimated at $31 \%$.

Physical examination demonstrated a blood pressure of $167 / 88 \mathrm{mmHg}$, and a heart rate of 100 to $105 \mathrm{bpm}$. Airway examination revealed a Mallampati class 2 airway. She was deemed to be ASA status IV. Pre-admission medications included: insulin (regular 8 units $\mathrm{q}$ am, 4 units q pm, NPH 26 units q am, 8 units q pm), metoprolol $50 \mathrm{mg}$ bid, albuterol, hydralazine $50 \mathrm{mg}$ tid, isosorbide dinitrate $20 \mathrm{mg}$ tid, furosemide $20 \mathrm{mg}$ bid, hydroxyurea $1 \mathrm{~g}$ qd and digoxin $0.25 \mathrm{mg}$ qd.

Pulmonary artery catheterization was performed and the initial pressures were: pulmonary artery (PA) 80/45 $\mathrm{mmHg}$, pulmonary artery wedge (PAWP) $35 \mathrm{mmHg}$, cardiac output (CO) $4.8 \mathrm{~L} \cdot \mathrm{min}^{-1}$; systemic vascular resistance (SVR) 900 dynes $\cdot \mathrm{cm} \cdot \mathrm{sec}^{-5}$. Due to her congestive heart failure, as evidenced by high pulmonary artery pressures, jugular venous distension, and bibasilar rales, it was decided to treat her medically. Diuresis was carried out with furosemide. The urine output was 9290 $\mathrm{ml}$ over the next two days and her weight decreased from 68.6 to $66.2 \mathrm{~kg}$. Her clinical status improved as did her cardiovascular variables showing PA pressure 34/20 mmHg, cardiac output $5 \mathrm{~L} \cdot \mathrm{min}^{-1}$, SVR 1150 dynes $\cdot \mathrm{cm} \cdot \mathrm{sec}^{-5}$, BP $167 / 70$, HR 100 , RR 20 to 24; ABG: pH 7.43, $\mathrm{PaCO}_{2} 36 \mathrm{mmHg}, \mathrm{PaO}_{2} 96 \mathrm{mmHg}$, $\mathrm{HCO}_{3}-25 \mathrm{mmol} \cdot \mathrm{L}^{-1}, \mathrm{SaO}_{2} 97.7 \%$.

Due to the recent onset of superimposed preeclampsia and a history of two previous abdominal deliveries, a repeat Caesarean section was planned. The fetus had shown adequate serial growth, estimated fetal weight of $2293 \mathrm{~g}$ and $\mathrm{L} / \mathrm{S}$ ratio of 1.9 . The patient refused epidural anaesthesia and requested general anaesthesia. Her two previous Caesarean sections had been performed under general and epidural anaesthesia respectively. Both were without complication.

Her vital signs immediately before surgery were BP 162/82 mmHg, HR $102 \mathrm{bpm}$, RR $18 \mathrm{bpm}$, PA pressure $67 / 25 \mathrm{mmHg}, \mathrm{CO} 5.2 \mathrm{~L} \cdot \mathrm{min}^{-1}$. Monitors included ECG (leads II and $\mathrm{V}_{5}$ ), pulse oximeter, peripheral arterial catheter, Foley catheter, and a pulmonary artery catheter. A nitroglycerin infusion was running at 0.1 $\mu \mathrm{g} \cdot \mathrm{kg}^{-1} \cdot \min ^{-1}$.

After bicitra $30 \mathrm{ml}$, metoclopramide $10 \mathrm{mg} i v$ and an albuterol inhaler (two puffs), the patient was given oxygen and, with constant cricoid pressure, general anaesthesia was induced using fentanyl $500 \mu \mathrm{g}$, thiopentone $150 \mathrm{mg}$, and tracheal intubation was facilitated with succinylcholine $100 \mathrm{mg}$. The Caesarean section began as soon as tracheal intubation was confirmed. Trans-oesophageal echo-cardiography was performed intraoperatively and the left ventricle showed good wall motion. Also noted were $2+$ mitral regurgitation and $2+$ tricuspid regurgitation.

The patient delivered a live male infant $14 \mathrm{~min}$ after induction of anaesthesia. The baby weighed $2435 \mathrm{~g}$ and had Apgar scores of 2 and 6 at one and five minutes respectively. The low Apgar scores were attributed to the fentanyl given at induction of anaesthesia. Cord blood

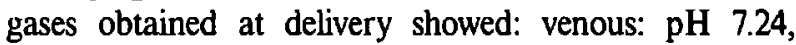
$\mathrm{PCO}_{2} 17 \mathrm{mmHg}, \mathrm{PO}_{2} 66 \mathrm{mmHg}$, arterial: $\mathrm{pH}$ 7.19, $\mathrm{PCO}_{2} 12 \mathrm{mmHg}, \mathrm{PO}_{2} 60 \mathrm{mmHg}$. Paediatricians from the Neonatal Intensive Care Unit were present for neonatal resuscitation. The baby required short-term (two hours) tracheal intubation and naloxone to reverse the fentanyl. The baby was then sent to the regular nursery. Maternal cardiovascular variables immediately after birth were: BP 122/72 mmH, HR $92 \mathrm{bpm}$, PA 34/27 mmHg, $\mathrm{CO} 4.6 \mathrm{~L} \cdot \mathrm{min}^{-1}$. Arterial blood gas analysis revealed pH 7.37, $\mathrm{PaCO}_{2} 38 \mathrm{mmHg}, \mathrm{PaO}_{2} 99 \mathrm{mmHg}, \mathrm{HCO}_{3} 23$ $\mathrm{mmol} \cdot \mathrm{L}^{-1}, \mathrm{SaO}_{2} 97.4 \% \mathrm{mmHg}, \mathrm{Na} 136 \mathrm{mmol} \cdot \mathrm{L}^{-1}, \mathrm{~K}+$ $4.2 \mathrm{mmol} \cdot \mathrm{L}^{-1}$, HCT $40.0 \%$. Serum glucose was 5 $\mathrm{mmol} \cdot \mathrm{L}^{-1}$. After delivery of the baby, the mother received $20 \mathrm{u}$ Pitocin $i v$ without any complications. The nitroglycerin infusion was titrated to maintain maternal blood pressure within the preoperative range of 0.1 to $0.5 \mu \mathrm{g} \cdot \mathrm{kg}^{-1} \cdot \mathrm{min}^{-1}$.

The Caesarean section was completed uneventfully and bilateral tubal ligation was also performed. The trachea was extubated at the conclusion of the operation. She received a total of $1200 \mathrm{ml}$ Ringer's lactate and $400 \mathrm{ml}$ DSLR. The estimated blood loss was $550 \mathrm{ml}$ and the urine output was $110 \mathrm{ml}$. The patient was returned to the Coronary Care Unit for postoperative monitoring. Nitroglycerin and sodium nitroprusside infusions were given for postoperative blood pressure control. A magnesium sulfate infusion was also begun. She had an uneventful postoperative course; there was no evidence of reinfarction. The invasive monitors were removed on the fourth postoperative day, and the patient was discharged with the baby on the seventh postoperative day.

\section{Discussion}

Acute myocardial infarction is a rare event during pregnancy. The estimated occurrence is one per 10,000 deliveries. ${ }^{1,2}$ Myocardial infarction occurring during preg- 
nancy was first described in $1922^{4}$ and 84 cases have been reported since. ${ }^{5}$ Approximately half have been in parturients over $35 \mathrm{yr}$ of age. Hankins et al. ${ }^{6}$ stated that maternal deaths occurred either at the time of infarction, with an undeliverable child, or within two weeks of infarction, usually in relation to the onset of labour and delivery. Postpartum myocardial infarction is associated with a high mortality, tending to occur in young primagravidas with preeclampsia.

It has been postulated by Sasse et al. ${ }^{7}$ that coronary artery spasm during pregnancy may result from a transiently ischaemic chorion, induced by decreased uteroplacental blood flow while laying supine during the third trimester of pregnancy. The human chorion contains 160 times more renin than maternal plasma. Subsequent coronary angiography in his reported cases proved to be normal.

Class H Diabetes is rare in pregnancy. It is defined as diabetes of any duration and age of onset accompanied by ischaemic heart disease. Siflen ${ }^{8}$ emphasized the poor outcome of these cases, and the risk factors for CAD in the diabetic patient such as obesity which together show altered carbohydrate metabolism, increased insulin resistance, and a high incidence of hypertension.

Silfen considers the "arterial age" to be equal to the chronological age plus the duration (years) of diabetes. In our patient this would put her arterial age at $67 \mathrm{yr}$, increasing the challenge of antenatal and intraoperative management.

The choice of anaesthesia and mode of delivery in the post-MI parturient is controversial. Cohen ${ }^{9}$ reviewed the advantages and disadvantages of vaginal vs Caesarean section delivery and found no advantage for either. The advantages of vaginal delivery include reduced surgical stress, decreased blood loss, early ambulation, and haemodynamic stability. The advantages of delivery by Caesarean section include avoidance of prolonged and unpredictable outcome of labour and the ability to time the delivery. ${ }^{10}$ The method of delivery needs to be individualized to the parturient depending on severity of diabetes, cardiac status and obstetric condition. For example, allowing a parturient to labour may cause hypertension and tachycardia secondary to inadequate pain relief and thus places increased demands on the myocardium.

Many reports state that the anaesthetic of choice is continuous epidural anaesthesia to the $T_{3}$ dermatomal level. ${ }^{5}$ It is felt that epidural anaesthesia blunts the haemodynamic response to the stress of labour or surgical stimulus. It is controllable, reduces blood loss and provides postoperative pain management. Furthermore, the sympathetic blockade of $T_{3}$ epidural analgesia results in a slower heart rate which minimizes myocardial oxygen demand. This mode of anaesthesia also alleviates the need for tracheal intubation with its risk of failure and gastric aspiration. A further consideration in this patient was her history of asthma. Epidural analgesia would also have elimiated the opioid induced neonatal respiratory depression that occurred. A fentanyl, thiopentone, succinylcholine rapid sequence induction was chosen to minimize the haemodynamic changes of a standard thiopentone, succinylcholine rapid sequence induction and intubation. The fact that this patient had undergone three previous laparotomies also favoured epidural anaesthesia, as she was more likely to have peritoneal adhesions, thereby prolonging the surgical incision to delivery time.

\section{References}

1 Ginz B. Myocardial infarction in pregnancy. $\mathrm{Br} \mathrm{J}$ Obstet Gynaecol 1970; 77: 610-5.

2 Fletcher E, Knox EW, Morton P. Acute myocardial infarction in pregnancy. BMJ 1967; 3: 586-8.

3 Aglio LS, Johnson MD. Anaesthetic management of myocardial infarction in a parturient. Br J Anaesth 1990; 65: 258-61.

$4 \mathrm{Katz} \mathrm{H}$. About the sudden natural death in pregnancy during delivery and the puerperium. Archiv fur Gynakologie 1922; 115: 283-312.

5 Hands ME, Johnson MD, Saltzman DH, Rutherford JD. The cardiac, obstetric, and anesthetic management of pregnancy complicated by acute myocardial infarction. J Clin Anesth 1990; 2: 258-68.

6 Hankins GDV, Wendall GD Jr, Leveno KJ, Stoneham J. Myocardial infarction during pregnancy: a review. Obstet Gynecol 1985; 65: 139-46.

7 Sasse L, Wagner R, Murray FE. Transmural myocardial infarction during pregnancy. Am J Cardiol 1975; 35: 448-52.

8 Silfen SL, Wapner RJ, Gabbe SG. Maternal outcome in class H diabetes mellitus. Obstet Gynecol 1980; 55: 749-51.

9 Cohen WR, Steinman T, Patsner B, Snyder D, Satwicz P, Monroy $P$. Acute myocardial infarction in a pregnant woman at term. JAMA 1983; 250: 2179-81.

10 Laughlin MP, From RP, Choi W. Recent myocardial infarction in a parturient. Discussion of risk, delivery alternatives and choice of anesthesia. Anesthesiology Review 1986; 13: 43-8.

11 Chestnut DH, Zlatnik FJ, Pitkin RM, Varner MW. Pregnancy in a patient with a history of myocardial infarction and coronary artery bypass grafting. Am J Obstet Gynecol 1986; 155: 372-3. 